\title{
La planificación del abastecimiento alimentario a la gran ciudad: Marchas y contramarchas del Mercado Central de Buenos Aires (1960-2019)
}

The planning of the great city' food supply: Progresses and backwards of the Central Market of Buenos Aires (1960-2019)

\author{
Joaquin Pérez Martin \\ Universidad de Buenos Aires, Facultad de Agronomía, \\ Cátedra de Sistemas Agroalimentarios, Buenos Aires, \\ Argentina / Universidad Nacional de San Martin, Instituto \\ del Transporte, Buenos Aires, Argentina \\ joapm@agro.uba.ar \\ Andrés Barsky \\ Universidad Nacional de General Sarmiento, Instituto del \\ Conurbano, Buenos Aires, Argentina \\ abarsky@ungs.edu.ar
}

\begin{abstract}
Resumen:
El presente artículo se propone realizar una sistematización histórica de la trayectoria del proyecto para la instalación del Mercado Central de Buenos Aires (1960-1984), que definió fuertemente el funcionamiento del centro de comercialización mayorista alimentario más importante del país, desde su inauguración en 1984 a 2019. La gobernanza del abastecimiento de alimentos para el Área Metropolitana de Buenos Aires demanda amplios consensos entre los actores sectoriales y los distintos niveles de gobierno que hasta la fecha no han podido consolidarse en un plan para aprovechar, ampliar a otros sectores alimentarios e impulsar esta gran obra de infraestructura que es el Mercado Central.

Palabras ClaVE: Abastecimiento de alimentos, Gobernanza metropolitana, Interacción rural-urbana, Mercados mayoristas de alimentos.
\end{abstract}

\section{ABstract:}

This article proposes a historical review of the trajectory of the project for the installation of the Central Market of Buenos Aires (1960-1984), which strongly defined the operation of the most relevant wholesale food market in the country, from its inauguration in 1984 until 2019. The governance of the Metropolitan Area of Buenos Aires food supply requires broad consensus between the sectoral actors and the different levels of government. Up to date, none of them were able to establish an agreed plan to leverage, include other food sectors and impulse this great infrastructure that is the Central Market.

KEYWORDS: Food supply, Metropolitan governance, Rural-urban interaction, Wholesale food markets.

\section{INTRODUCCIÓN}

La discusión en torno a la necesidad de ordenar el abastecimiento de alimentos de la Capital Federal -hoy Ciudad Autónoma de Buenos Aires (CABA) - y su entorno regional remite a distintos momentos del siglo XX. Comienza a adquirir relevancia en ámbitos técnicos y políticos desde la década de 1960, teniendo en consideración una perspectiva más metropolitana de los fenómenos aglomerativos urbanos, que venía siendo crecientemente incorporada en iniciativas de planificación oficial, particularmente entre los períodos 1932-1945 y 1948-1950 (Barsky, 2014; OPR, 1968). Caride (1999) identifica que, hacia fines de los años cuarenta, comienzan a ensayarse respuestas de carácter interjurisdiccional para distintas problemáticas que 
emergían al compás del proceso de expansión de la gran ciudad, hoy identificada como Área Metropolitana de Buenos Aires (AMBA). La definición más extendidamente utilizada del AMBA es la que incluye a la CABA, capital del país y ciudad-Estado de rango similar a una provincia, y los 24 partidos -equivalentes a departamentos o municipios- del conurbano de la provincia de Buenos Aires, donde según proyecciones al 2019 residían 14,2 millones de personas (32 \% de la población nacional) (INDEC, 2020c). El AMBA constituye un territorio extenso, disperso, desigual y heterogéneo (Pírez, 2005), donde el consumo alimentario es el principal gasto hogareño (INDEC, 2019) y, para 2019, $23 \%$ de la población se encontraba en una situación de inseguridad alimentaria severa ${ }^{1}$ (ODSA-UCA, 2019). Tratándose de un territorio donde confluyen múltiples instancias de decisión, con atribuciones formales -que en muchos casos se superponen pero que también resultan desatendidas por los distintos niveles de gobierno-, encauzar procesos de gobernanza resulta un desafío no exento de complejidad, máxime en regiones urbanas de semejante envergadura, tal como acontece en otras realidades de Latinoamérica. De esta forma, aplicándolo al abastecimiento alimentario del AMBA, la gobernanza hace referencia a la acción pblica para garantizar "la articulación estable de actores interdependientes y operacionalmente autónomos del triángulo Estadomercado-sociedad civil" (Navarrete Ulloa, 2020, p. 9).

El presente artículo se propone realizar una sistematización histórica de la trayectoria del proyecto para la instalación del Mercado Central de Buenos Aires (MCBA) (1960-1984), abordando sus implicancias técnicas y políticas, a fines de analizar cómo las mismas han incidido en la operatoria desde su inauguración en 1984 hasta la actualidad (1984-2019). El trabajo propone aportar elementos de análisis que contribuyan a la comprensión de ese proceso, cuyo resultado fue un tipo de diseño que pautó decisivamente el funcionamiento de la infraestructura pública para la comercialización alimentaria más importante del país. A los fines de este cometido, se realizó una revisión bibliográfica de documentos técnicos del proyecto, artículos académicos, diarios y revistas, así como de normativa, legislación y documentos de gobierno, generados tanto durante los períodos democráticos como los de facto. Los documentos más importantes, generados en el ámbito de la entonces Comisión de Asesoramiento Legislativo (CAL) constituida entre 1976 y 1983, fueron consultados en el Archivo General de la Nación. A su vez, la información de fuentes secundarias se complementó con entrevistas en profundidad realizadas a referentes sectoriales y políticos vinculados al proyecto de creación del Mercado y su posterior puesta en marcha.

\section{ORIGEN Y TRAYECTORIA DEL PROYECTO DEL MCBA: DECISIONES DE FACTO, TRANSICIONES CIVILES}

El proyecto del MCBA estuvo originalmente enmarcado en la Organización del Plan Regulador de Buenos Aires, en el ámbito de la Municipalidad de la Capital Federal (OPR, 1968). En este contexto, con la atención puesta principalmente en el Mercado de Abasto -aunque también se destacaban en importancia los mercados Dorrego, Ciudad de Buenos Aires, Saldías y Nacional de Papas- queda definida la intención de terminar con la actividad comercial mayorista, tanto por razones urbanísticas, de tránsito, de higiene y seguridad urbana, como así también con el objetivo de mejorar la operatoria del abastecimiento alimentario. En aquel momento, en todo el entorno del AMBA había más de 20 mercados mayoristas, 8 dentro del ejido de la ciudad y los restantes en el conurbano bonaerense. En este período se modernizan las normativas comerciales y sanitarias no solo para el abastecimiento mayorista de alimentos, sino también para la comercialización minorista, autorizándose los negocios polirubro (por ejemplo, se habilita a las carnicerías a vender panificados, fiambres y quesos), como primer antecedente del supermercadismo. Asimismo, se prohíbe la venta de leche cruda, obligando a su pasteurización, y se promueve la venta de carne trozada y envasada, buscando evitar el ingreso de medias reses a la capital (Frigerio, 1973; MCBA, 1960a, 1960b, 1961, 1964).

En este contexto, en 1961 la Municipalidad encarga al Consejo Federal de Inversiones (CFI) la realización de un estudio, que contó con el asesoramiento de especialistas de la Société Centrale pour l'Equipement 
$d u$ Territoire (SCET), un consorcio público francés. SCET contaba con una vasta experiencia en el tema dado que estaba planificando y construyendo una gran cantidad de mercados en Francia, que desde 1953 se encontraba reformando su sistema de distribución de alimentos a escala nacional, bajo la denominada política de "Mercados de Interés Nacional". Tomando como referencia, especialmente, la experiencia del nuevo mercado mayorista Rungis, en las afueras de París, que estaba en construcción y sería finalmente inaugurado en 1969, el estudio sienta las bases que estructurarán el desarrollo del proyecto del MCBA. Aunque este enfatiza la necesidad de planificar el abastecimiento alimentario, en la práctica, propone y desarrolla una única alternativa de alcance metropolitano: concentrar la oferta y la demanda mayorista de una serie de sectores alimenticios en un solo mercado, el cual debía estar dotado de un perímetro de protección monopólico (CFI, 1962).

Mientras el estudio avanzaba, se trabajaba en la determinación de la localización del futuro mercado único, tal como ya había sido acordado. Dada la falta de terrenos adecuados en la Capital Federal, "se orientó su búsqueda hacia el Gran Buenos Aires" en un área con buenos accesos tanto automotores como ferroviarios para la introducción y distribución de cargas (ERMCBA, 1963a, p. 18). De esta forma, se define la localización del futuro mercado por su posición geográfica, por la disponibilidad de terrenos de amplia superficie ( 520 hectáreas) y por las facilidades que presentaba para llevar a cabo actividades de abastecimiento y desconcentración, en la primera corona del conurbano y en el eje sudoeste del AMBA. Asimismo, se definió un primer diseño del MCBA, que en sus orígenes estaba previsto que concentrara frutas, hortalizas, legumbres, pescados, aves y productos lácteos (CFI, 1962).

Hacia 1962 se le transfiriere a la Municipalidad de la Ciudad de Buenos Aires la atribución de organizar el abastecimiento de alimentos en el ámbito de la Capital Federal, habilitando las futuras decisiones respecto a los mercados allí instalados (PEN, 1962a). A su vez, se formaliza un acuerdo con 22 municipios del conurbano, avanzando hacia un primer esquema operativo de organización metropolitana en cuestiones de abastecimiento alimentario (ERMCBA, 1963a).

El estudio realizado por CFI y SCET concluye que se "ha demostrado la conveniencia de crear un mercado central, destinado a recoger la oferta y la demanda en un solo ámbito (...) permitiendo la expresión del precio real", a partir de la cual la Municipalidad crea una comisión para iniciar el proyecto del MCBA. La misma tiene como objetivo estudiar y analizar tanto el proyecto como su financiación: lo integran el CFI, el gobierno de la provincia de Buenos Aires y las secretarías nacionales de Comercio; Agricultura y Ganadería; y de Transportes (ERMCBA, 1963a, p. 70). Como primera medida se prohíbe el emplazamiento de nuevos mercados mayoristas de alimentos tanto en el ámbito de la Capital Federal como en los 22 municipios del Gran Buenos Aires (PEN, 1962b; PEPBA, 1962). Una cuestión importante que apareció en el camino tuvo que ver con la ingeniería institucional que se requirió para que una iniciativa de la Ciudad de Buenos Aires se implementara en una jurisdicción externa a ella, tomando alcance metropolitano: desde la Nación se realizó una intervención federal en la Provincia de Buenos Aires para que el conurbano bonaerense se adecue a la prohibición de autorizar el funcionamiento de nuevos mercados mayoristas (PEN, 1962b, p. 435).

En 1963 se crea, en el ámbito de la Municipalidad, el Ente Realizador del Mercado Central de Buenos Aires (ERMCBA), el cual tiene por objeto el emplazamiento de un mercado concentrador, aunque con capacidad para que "sus establecimientos [puedan] ser instalados en cualquier punto del país", perfilándose ya como un ente metropolitano. En paralelo, el mismo consorcio CFI-SCET avanza con el primer anteproyecto, esquematizando las "superestructuras" destinadas a los siguientes rubros: frutas, hortalizas, aves, huevos, manteca, queso, pescado y embalaje. Con la creación del ERMCBA, se declaran de utilidad pública y sujetos a expropiación los terrenos para la instalación del futuro mercado en el partido de La Matanza. Al poco tiempo, la iniciativa del ERMCBA encuentra límites para su funcionamiento ya que, al ser un organismo del ámbito de la Municipalidad, no podía ejercer su autoridad, ni dictar normas complementarias en el futuro mercado, siendo que estas atribuciones correspondían a las autoridades locales o de la provincia de Buenos Aires (ERMCBA, 1963b, 1963a, p. 63; PEN, 1963; PEPBA, 1963). 
Durante el período de gobierno del presidente Arturo Illia (1963-1966), el proyecto del MCBA no registró avances, al menos en función de lo que se desprende de la documentación existente y los testimonios recogidos. De acuerdo a algunas notas de prensa de la época, el proyecto no contaba con una valoración positiva, tanto por su elevado costo (US\$ 207 millones a valores constantes ${ }^{2}$ ) como porque “la concentración obligatoria implicaría un atentado contra la libertad de comercio", lo que llegó a poner en duda la continuidad del ERMCBA (Argentina, paraíso de los especuladores, 1964, párr. 10; Miscelánea política, 1965).

Hacia 1967, en el marco del gobierno de facto de la Revolución Argentina, el proyecto del MCBA vuelve a tomar impulso y el ERMCBA se disuelve para convertirse en la actual Corporación del Mercado Central de Buenos Aires (CMCBA). La CMCBA queda conformada como una entidad pública interestadual, con capacidad de derecho público y privado, integrada por los gobiernos de la Nación, de la Provincia de Buenos Aires y de la Municipalidad de la Ciudad de Buenos Aires en partes iguales, que tendrá por objeto proyectar, construir y administrar un mercado único concentrador. Esta medida contó con el apoyo del Consejo Nacional de Desarrollo y de la Junta de Gobernadores de la Región de Desarrollo del Área Metropolitana, con la expectativa que al nuevo mercado acudieran "los sectores mayoristas y minoristas, (y que) mediante la creación de un medio en el que la oferta pueda concurrir con toda libertad y amplitud, (...) los precios que se fijen por el libre juego serán los que correspondan” (MCBA, 1967; PEN, 1967, párr. 2).

A partir de la creación de la CMCBA, el proyecto comienza a tomar un gran impulso. Se conforma el directorio, y entre 1969 y 1971 comienzan a realizarse una gran cantidad de estudios específicos y complementarios. En 1971, cuando ya se habían realizado erogaciones por US\$24,3 millones a valores constantes de febrero 2020, lo que representó 4,1 \% de la inversión total registrada por la CAL (1980), se estimaba que las obras estarían concluidas en 1974 (CMCBA, 1971a). En este contexto, entre los lineamientos del Plan Nacional de Desarrollo y Seguridad 1971-1975 se incluye la conformación de un "sistema nacional de concentración de alimentos perecederos, estructurado sobre la base de mercados regionales”, vinculándolo con los lineamientos de política agropecuaria que allí se planteaban (PEN, 1970, párr. 104).

En 1971 se sanciona la Ley de Mercados de Interés Nacional (MIN), dándole un marco legal de funcionamiento al futuro mercado mayorista. La misma establece un "régimen para promover y perfeccionar una red de mercados mayoristas de gravitación regional o nacional”, siendo el MCBA el primero en ser declarado como un servicio público (PEN, 1971, párr. 1). En función de la impronta francesa que tuvo el proyecto desde sus orígenes la denominación de la política de MIN toma el nombre de la francesa Marché d'Intérêt National. La autoridad de aplicación tenía, y tuvo hasta su desregulación en 1991 (PEN, 1991), la capacidad para definir la localización y la operatoria de los mercados mayoristas, fomentar la incorporación de cooperativas o asociaciones y facilitar el acceso a los comerciantes minoristas. A su vez, se destaca la capacidad que tenía para determinar y modificar perímetros de protección -monopólicos- para cada uno de los mercados de interés nacional. Este perímetro les confiere exclusividad sobre ese territorio, la imposibilidad de funcionar fuera del mismo y la obligación, para los comercios minoristas ubicados dentro del radio, de proveerse de ese centro de abasto.

Hacia comienzos del año 1972, se redefine el perímetro de protección del MCBA, retirándose del sur, para dar lugar al perímetro de protección del Mercado Regional de La Plata que se inauguraría ese mismo año. En esa área quedaba prohibida la habilitación, ampliación y/o traslado de mercados mayoristas y se dispuso que el MCBA tomaría intervención en el abastecimiento de frutas, hortalizas, pescados, mariscos, aves y huevos, dejando abierta la posibilidad de que a futuro se incluyera dentro de este esquema tanto la carne vacuna como los productos lácteos. A su vez, se definió que la puesta en funcionamiento del perímetro de protección se anunciaría con 9 meses de anticipación a su entrada en vigencia, de modo de dar tiempo a los mercados que estaban en funcionamiento a mudar sus operaciones al MCBA y proceder con su cierre (CAL, 1983b).

Hacia 1973, el proyecto del Mercado experimenta marchas y contramarchas entre el gobierno nacional y el de la Municipalidad: los mercados de Abasto, Saldías, Ciudad de Buenos Aires, Demarchi, Liniers y 
Vélez Sarsfield se integran a la red de MIN, mientras que el gobierno local venía trabajando intensamente para su cierre (PEN, 1973c). Posteriormente, se intervienen y declaran como MIN a 24 mercados del conurbano bonaerense y algunas salas de remates de frutas, aunque se aclara que "la CMCBA (...) encargada de ordenar los abastecimientos del Gran Buenos Aires, resulta el órgano apropiado para dirigir a los mercados actualmente en funcionamiento, cuya actividad debe ser substituida -dentro del menor plazo posible- por la del Mercado Central" (PEN, 1973a, párr. 3, 1973b). En el marco del Plan Trienal para la Reconstrucción y Liberación Nacional, que incorporaba la política alimentaria entre sus principales lineamientos, se plantea la habilitación del MCBA como uno de los instrumentos principales en materia comercial, estimándose que estaría listo en 1976 (PEN, 1973d).

En 1974, la Organización de Naciones Unidas para la Agricultura y la Alimentación (FAO) presenta un estudio que tenía por objetivo asesorar al gobierno argentino en la operación del futuro mercado. Este organismo venía impulsando ambiciosos planes de modernización y desarrollo de nuevas infraestructuras de comercialización, tomando como referencia lo que venía sucediendo en las grandes ciudades del mundo que inauguraban nuevos mercados mayoristas, tales como Nueva York (1967), Boston (1969), Rotterdam (1969), París (1969), Barcelona (1971) y Viena (1972) (Seidler, 2001). El informe presentado se oponía al proyecto de concentrar la operación mayorista frutihortícola en un único mercado, en un contexto en el que la construcción del MCBA avanzaba lentamente. En cambio, recomendaba un sistema de tres mercados mayoristas, dividiendo las operaciones en un mercado principal y dos secundarios (Link, 1974). Esta postura fue también compartida por el especialista argentino Norberto Frigerio, quien se desempeñaba en el Instituto Interamericano de Cooperación para la Agricultura (IICA) (Frigerio, 1973, 1976). Así, en virtud de estos cuestionamientos al proyecto, la CMCBA analizó otros alternativos, aunque encontró que el proyecto que obtuvo el mejor "índice de preferencia" fue el que recomendaba concentrar la totalidad de las operaciones en un único mercado (CMCBA, 1973, p. 4.7; Pérez Martín, 2015).

Entre 1972 y 1975 se registra una inversión equivalente a US\$102,8 millones, calculándolo a valores constantes a febrero 2020, lo que representa $17,5 \%$ de la inversión total registrada entre 1967 y 1980. Durante ese período no hay indicios que la construcción de las naves del MCBA se hubiera iniciado, aunque sí tuvieron lugar los primeros movimientos de suelos en el muy amplio terreno. También se emprendió la construcción de obras hidráulicas y caminos, y se contrató un importante número de consultorías y estudios (CAL, 1980).

\section{El proyecto del MCBA durante el Proceso de Reorganización Nacional: IMPULSO A LA OBRA}

Con el advenimiento de la dictadura del Proceso de Reorganización Nacional, en marzo de 1976, el proyecto del MCBA adquiere un nuevo impulso. Tan es así que el primer día hábil de gobierno, se interviene la CMCBA. Dos meses y medio más tarde, cesa la intervención y se designan directores bajo una estructura de representación cívico-militar. En este contexto, la construcción del mercado continúa avanzando, hacia 1977 las obras básicas estaban ya concluidas, mientras que comenzaba la construcción de las naves de comercialización de frutas, hortalizas, pescados y mariscos.

Tal como ya había sucedido, aunque ahora con la obra del MCBA en marcha, se intenta ordenar el funcionamiento de los mercados mayorista de la Capital Federal y el conurbano bonaerense -que debían cerrar, tal como estaba planteado-, en el marco de la política de MIN, clasificándolos en tres grupos: mercados introductores especializados, mercados Introductores polivalentes y mercados distribuidores polivalentes (CAL, 1980; SCyNE, 1977). Entre los años 1976 y 1980, la ejecución de la obra del MCBA registró su máximo avance en cuanto a la inversión realizada, alcanzando la ejecución del 78,6\% de la inversión total para la construcción del Mercado, la cual ascendió, a valores constantes de febrero 2020, a US\$593,8 millones (CAL, 1980; US Bureau of Labor Statistics, 2020). La inversión fue realizada casi en su totalidad por el 
gobierno nacional, en un $95 \%$, mientras que un $4 \%$ fue aportado por la Provincia de Buenos Aires y lo restante por la Municipalidad de la Ciudad de Buenos Aires, la principal jurisdicción impulsora de la iniciativa. En lo referido a las fuentes de financiamiento, vale destacar la escasa información que existe al respecto: Calcagno (1987) incluye a la CMCBA entre los principales organismos tomadores de deuda externa del sector público, mientras que Pons (comunicación personal, 21 de junio de 2016) agrega que parte del financiamiento provino del Euro Latin American Bank - Eulabank.

A fines del año 1980, la obra estaba prácticamente finalizada y el MCBA se encontraba en condiciones operativas de ser inaugurado. En paralelo se inauguran las autopistas 25 de Mayo y Perito Moreno, las cuales se habían comenzado a construir en 1978 y formaban parte del Plan de Autopistas que se enmarcaba en el Código de Planeamiento Urbano de 1977 (Jajamovich \& Menazzi, 2012). Estos flamantes corredores eran fundamentales para fortalecer la accesibilidad al Mercado de la producción que provenía desde los ejes sur y sudeste, como La Plata.

A partir de ese momento vuelven a emerger las discusiones que venían teniendo lugar desde los orígenes del proyecto, aunque con la diferencia que, después de 20 años, el mercado podía empezar a funcionar. La controversia más importante estaba relacionada con la implementación del perímetro de protección, que implicaba el cierre de los 23 mercados frutihortícolas que estaban funcionando a nivel metropolitano. Gauto \& Ninin (1979, pp. 214-217) destacan algunos de los planteos que, desde diversos sectores, se realizaron en oposición al proyecto, señalando que el proyecto del MCBA "es un simple traspaso de un fracaso, que es el Mercado de Rungis, de Francia”. A su vez, se cuestionaba el grado de involucramiento estatal en la comercialización, alegando que el perímetro de protección era anticonstitucional, "ya que atenta contra la libertad de comercio y porque está alterando algo que hoy en día todos los países del mundo tratan de fomentar, como es el canal directo de comercialización, desde el productor al consumidor". A su vez, los medios de prensa destacaban los problemas de "carácter jurídico y económico" que se le presentarían al gobierno una vez concluida la obra. El cuestionamiento principal se originaba con la puesta en marcha del perímetro monopólico que implicaba el traslado de los 2.200 operadores mayoristas al nuevo mercado, con el riesgo de tener que afrontar cuantiosos juicios e indemnizaciones. La apertura del MCBA contaba con el apoyo de un conjunto de productores que se habían agrupado en lo que se llamó el Consejo Coordinador Frutihortícola, integrado por distintas organizaciones de productores. Estas entidades señalaban la importancia de la concentración de actividades comerciales en el MCBA, a los fines de promover la transparencia y fiscalización de las operaciones para que "se forme un precio real", y destacaban la importancia del perímetro de protección para que los operadores mayoristas puedan "cumplir una función razonable económicamente dentro del circuito productivo", evitando que funcionen como una "intermediación parasitaria", eslogan que se popularizaría para identificar a los opositores a la apertura del MCBA (CAL, 1983a, f. 134-135, 150). En cambio, entre los detractores de la apertura del MCBA como único mercado concentrador se encontraba la Cámara Argentina de la Actividad Frutihortícola (CAAF), que había presentado un recurso de amparo basado en "la libertad de trabajo, en tener un recinto físico donde operar, ya que la capacidad del MCBA es limitada (...) hay otras razones (...) de operatividad, de idiosincrasia del minorista que opera en el área metropolitana, que también pesan” (CAL, 1983a, f. 118-119). También aparecen iniciativas para privatizar el flamante mercado, aduciendo que la inversión pública que se había realizado durante 10 años aún no se había puesto en marcha y que no había un plan claro para la apertura (Búscase el modo de operar el Mercado Central, 1980, párr. 22). Desde el CFI se estudian modalidades operativas alternativas para el funcionamiento del MCBA (Pons, 1981). Entre las opciones que se evalúan, se incluye una propuesta de privatización del MCBA que se elevó a la Presidencia de la Nación, la cual venía siendo discutida apenas finalizada la obra (HCDN, 1983, f. 5).

Las presiones a favor y en contra de la puesta en funcionamiento del MCBA y el cierre de los restantes mercados provenían tanto de productores, transportistas, changarines y comerciantes mayoristas y minoristas, como de las autoridades políticas locales, particularmente del conurbano bonaerense, donde se 
radicaban más de 15 mercados, así como de funcionarios provinciales y nacionales. La interjurisdiccionalidad involucrada en el proceso, complejizaba la situación y hacía peligrar su apertura. La postura intransigente del entonces intendente de facto de la Ciudad de Buenos Aires, Osvaldo Cacciatore, respecto a que "el problema de los mercados trataría de resolverlo con las topadoras" (CAL, 1983a, f. 159), fue ratificada por su sucesor Guillermo Del Cioppo. Por su parte, la posición del gobierno de facto bonaerense fue alternando: Ibérico Saint Jean, se oponía a la apertura del MCBA como mercado único. Con la obra prácticamente finalizada, su reemplazante, Oscar Gallino, se diferencia de su antecesor y presta su conformidad para que el MCBA comience a operar, pero su mandato fue breve. Es luego sucedido por Jorge Aguado, quien viniendo desde el gremialismo agropecuario de la Confederación de Asociaciones Rurales de Buenos Aires y La Pampa (CARBAP), nuevamente se opondría al funcionamiento monopólico del flamante mercado (CAL, 1983a). Es decir, las críticas surgían por proponer mecanismos que intervinieran en las dinámicas económicas, lo que resultaba alineado con el espíritu liberal de las políticas de Martínez de Hoz. En este sentido, Braun Estrugamou (1981, pp. 55-59) planteaba si "los problemas de la comercialización frutihortícola eran de tal gravedad que hicieron necesaria la intervención del Estado. También, si la forma en que intervino el Estado fue la correcta y más aún, si no será peor el remedio que la enfermedad". Asimismo, agregaba que "por razones de bien común el Estado puede y debe corregir y encauzar el libre desarrollo de la actividad privada (...) pero razones de eficiencia económica no justifican la creación de un monopolio estatal (...) propias de una sociedad colectivista".

Intentando poner punto final a las discusiones, se dispone la habilitación del MCBA a partir del $1^{\circ}$ de diciembre de 1982, por lo que la Provincia y la Ciudad debían prohibir, desde esa fecha, el funcionamiento de los mercados mayoristas y obligar a poner en práctica el perímetro de protección, concentrando todos los ingresos de frutas y hortalizas en el MCBA. Sin embargo, en julio de 1982, una vez finalizada la Guerra de Malvinas, se dio marcha atrás con el anuncio de apertura, aduciendo que se había organizado "una gran campaña para desprestigiar al proyecto, alegando que era de corte estatista” (CAL, 1983a, f. 156).

Una vez anunciada la convocatoria a elecciones generales, en marzo de 1983 se firma un convenio en el que se establecen tres etapas para la apertura definitiva del Mercado. La primera comprendía la comercialización de papas, cebollas y ajos, la segunda sumaba a pescados y mariscos mientras que, la tercera y última, al resto de los productos frutihortícolas (CAL, 1983a). La puesta en funcionamiento de la primera etapa se hizo efectiva en mayo de 1983 y se utilizaron 3 de las 17 naves del mercado. Entre las medidas previstas para la apertura se incluía la implementación de un perímetro exclusivo y el uso de pago centralizado para las tres hortalizas mencionadas, aunque solo para la primera venta. Es decir, el resto de los operadores mayoristas seguían funcionando y los minoristas podían abastecerse libremente, tanto del MCBA como de otros mercados mayoristas, los cuales podrían realizar las sucesivas ventas. Esta innovadora adaptación de la normativa procuraba mantener un equilibrio entre las posiciones que estaban a favor de sostener el monopolio territorial del MCBA y las que pretendían eliminarlo por completo. A su vez, por primera vez, se controlaría la calidad y tipificación de la mercadería, tendiendo a establecer parámetros mínimos, y se implementaría un sistema de información de periodicidad diaria y semanal mediante el cual se daría a conocer la evolución de los precios y los volúmenes de ingreso al Mercado (Ratifican que el Mercado Central, 1983). Esta medida implicó el cierre del Mercado Nacional de Papas, Casa Amarilla, ubicado en el barrio de La Boca de la ciudad de Buenos Aires, del cual ya en 1981 se había establecido el cese de sus actividades, así como del Mercado de Valentín Alsina. La segunda etapa de la apertura estaba prevista para el mes de agosto de 1983 y así aconteció. La misma implicó el cierre del entonces Mercado de Concentración Mayorista de Pescado, ubicado en el barrio de Barracas. A su vez, en el transcurso de este año se implementaría la reducción del $8 \%$ al $2 \%$ de la alícuota diferencial del Impuesto al Valor Agregado (IVA). Tal medida estaba destinada a la comercialización de alimentos perecederos realizada a través de los MIN, con el objetivo de fortalecer el funcionamiento del MCBA. Así, se preveía un incremento de ingresos en el erario público a pesar de la reducción de la alícuota, dado que "la evasión es casi total" en el sector frutihortícola. Su fin no era recaudatorio, sino que, en virtud 
de la obligatoriedad de la concentración comercial mayorista en el MCBA, se buscaba transparentar los mecanismos comerciales, evitar la intermediación, proveer información de mercado y acortar la cadena de pagos a 72 horas, a través de la bancarización de las operaciones (CAL, 1983a, f. 51). La tercera y última etapa estaba planificada para el mes de diciembre del mismo año, cuando se instalaría el sistema informático, aunque esta no llegó a cumplirse; a último momento se dio una serie de amenazas y un intento de secuestro al entonces presidente de la CMCBA con el objetivo de acelerar la apertura total del MCBA con su perímetro de protección, ya que "se acercaban las elecciones de 1983 y pretendían quedarse con el control del Mercado, dado que tenían vinculaciones con la operatoria comercial del Aeropuerto de Ezeiza" (Martínez de Vedia, comunicación personal, 15 de julio de 2016). En definitiva, la tercera etapa no llegó nunca a materializarse, dado que resultaba imposible cumplir con los plazos necesarios para llevar a cabo la inauguración antes de la entrega del gobierno. Esto evidencia que la apertura parcial parece haber sido más una medida forzada, tanto por el hecho de que el Mercado llevaba más de dos años con la obra finalizada y sin poder operar, como por determinadas presiones políticas, que un intento de implementar un nuevo modelo de comercialización mayorista.

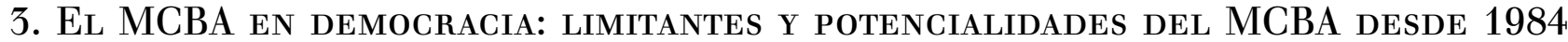 A 2019}

En los tiempos previos a las elecciones de 1983 la cuestión del MCBA se incluye en las plataformas electorales de los principales candidatos. Finalmente, cuando asume Alfonsín, la obra del mercado estaba prácticamente finalizada y la apertura parcial que se había concretado previamente era considerada apenas como un ensayo, pero no como un antecedente significativo (Pellegrini, comunicación personal, 30 de mayo de 2016). En la transición hacia la democracia no existió ninguna instancia de negociación en el traspaso de funciones y Alfonsín, sosteniéndose en el amplio apoyo popular con que contaba el nuevo gobierno democrático, cumple con su promesa de campaña y encara la tarea de llevar adelante la apertura definitiva del MCBA (Alconada Sempé, comunicación personal, 5 de febrero de 2016; Campero, comunicación personal, 11 de mayo de 2016).

$\mathrm{Al}$ poco tiempo de asumido el nuevo gobierno, ya había quedado definido el sistema de comercialización a implementar, y se contaba con la infraestructura y el personal necesario para abrir el mercado. Lo único que restaba para que el MCBA pudiera funcionar a pleno era la instalación de las divisiones de las naves y la implementación del sistema informático. Más allá de la cuestión operativa, para el gobierno la cuestión del MCBA constituía, claramente, un tema menor dentro de la compleja agenda política y económica post dictadura (Campero, 2016). El gobierno debía garantizar la conformación de un contrapeso político que incline la balanza para poder realizar la apertura del MCBA, de modo de neutralizar la iniciativa de los mercados del conurbano que estaban funcionando y venían oponiéndose al proyecto desde sus orígenes, como los mercados de Avellaneda, Tres de Febrero y Beccar. En ese momento, esos tres distritos eran gobernados por intendentes radicales, y Avellaneda, particularmente, había sido fundamental para la victoria de Alfonsín. Es decir, las circunstancias no eran las más propicias para avanzar hacia la apertura. Sin embargo, el apoyo a la iniciativa de Alfonsín hizo posible encauzar este proceso, a diferencia de lo que había acontecido durante la dictadura (Campero, 2016).

Las semanas previas a la apertura del MCBA fueron de gran intensidad política para monitorear posibles operaciones en contra de la apertura. Se interviene la CMCBA, mientras que el Secretario de Comercio recibe amenazas en su domicilio particular. La presión de la "patria verdulera", como se llamaba a los detractores del MCBA, se hizo sentir a tal punto que llevaron a cabo un lockout, clausurando las operaciones de los restantes mercados y poniendo en riesgo la provisión de frutas y hortalizas en todo el AMBA. Ante esto, en los andenes del MCBA se organizó un operativo de emergencia con apoyo de los gobernadores del interior del país, quienes despachaban camiones cargados de mercadería (Campero, 2016; Pellegrini, 2016). En los días 
previos a la apertura, y tal como estaba previsto (PEN, 1971; PEPBA, 1984), dejarían de operar los mercados mayoristas existentes, de acuerdo al perímetro de protección establecido, y se conformarían 24 cooperativas de changarines, una por cada uno de los mercados que se cerraban, para integrarse al MCBA. El perímetro abarcaba la Capital Federal y 26 municipios del conurbano para la primera venta de toda mercadería que ingresara al canal mayorista, mientras que, para el aprovisionamiento minorista, la obligatoriedad de acudir al MCBA incluía la Capital Federal y solo 13 municipios del conurbano. A su vez, había otros 5 municipios, donde las verdulerías podrían abastecerse tanto del MCBA como del Mercado de La Plata. En la ciudad de Buenos Aires, el Mercado del Abasto cerró sus puertas un día antes de la inauguración del MCBA: "Hoy, por imposición municipal, el tradicional Mercado de Abasto debe cesar su actividad como tal (...) los edificios del ahora viejo Mercado de Abasto serán conservados y adaptados a un nuevo destino" (S.A. Mercado de Abasto Proveedor, 1984, párr. 3). En algunos de los mercados frutihortícolas del conurbano se registró tal resistencia al cierre que fue necesario recurrir a la intervención de las fuerzas federales de seguridad. Los mercados de Beccar y Avellaneda encabezaron la oposición a esta medida, funcionando de manera parcial y clandestina. Desde el gobierno se establece una suerte de pacto implícito con los intendentes de esos distritos, apostando a que el funcionamiento del MCBA los terminaría ahogando y, que, por ende, no sería necesario confrontarlos políticamente para forzar su clausura (Campero, 2016; Pellegrini, 2016).

Finalmente, el MCBA queda inaugurado el 15 de octubre de 1984. Alfonsín ordena que se invite a los militares que habían sido parte de la CMCBA, asistiendo un representante por cada una de las fuerzas. Por su parte, se convocó a los gobernadores peronistas de las zonas de producción frutícola, como los de las provincias de Corrientes, Tucumán, Río Negro y Mendoza, y se promovió la concurrencia de miles de productores (Winograd, comunicación personal, 23 de marzo de 2016). El presidente de la FAA Humberto Volando y el gobernador de Tucumán Fernando Riera fueron los primeros oradores. En el cierre, el presidente Alfonsín (1984) destacaba:

Parecía que iba a resultar imposible (la apertura del MCBA) (...) tenemos que poner el hombro a una obra que, sin duda, va a facilitar el desarrollo de nuestra lucha contra la inflación, (...) nuestro sistema de comercialización es uno de los más antiguos que existe hoy en el mundo.

Con la inauguración del MCBA, los distintos operadores mayoristas y comerciantes minoristas comienzan a experimentar dificultades para seguir funcionando, en virtud de la obligatoriedad de la concentración de las actividades y el consiguiente cierre de los demás mercados mayoristas del conurbano. El MCBA sería el primer mercado en contar con controles de calidad, lo que significaba un importante avance (Fernández Lozano, comunicación personal, 27 de noviembre de 2020). Sin embargo, a pesar de la implementación del perímetro de protección, se mantuvo la actividad, de manera parcial y clandestina en, al menos, 9 mercados frutihortícolas del conurbano, que continuaron funcionando (Grenoville, Radeljak, \& Bruno, 2019). Como señala Viteri (2010), el proyecto del MCBA, planificado más de 20 años antes de su apertura, se trató de una buena idea aunque, finalmente, implementada en el momento inadecuado. Con el paso del tiempo, los principales instrumentos que se habían promovido a la hora de poner en funcionamiento el MCBA fueron desactivándose: la bancarización de operadores y consignatarios, un sistema de facturación especial y unificado, el servicio de pago centralizado en caja única e informatizada, la reducción de la alícuota del IVA, e incluso el perímetro de protección. La creciente informalidad con la que operaba el MCBA, y la persistencia de los restantes mercados mayoristas del conurbano que habían resistido su clausura, terminaron generando una red de mercados a escala metropolitana crecientemente atomizada. A excepción de los primeros meses desde su apertura, el MCBA continuó funcionando con un rol desdibujado, respecto al esquema original, en el abastecimiento frutihortícola nacional y del AMBA, perdiendo peso específico como mercado de referencia sectorial y regional.

A partir de la década de 1990, la consolidación del neoliberalismo económico trajo aparejada una desregulación generalizada de las actividades comerciales. De esta manera, se deroga la reducción de la alícuota 
del IVA (PEN, 1990) y con el Decreto de Desregulación Económica (PEN, 1991, párr. 28) se deja sin efecto el perímetro de protección del MCBA, aduciendo que "la experiencia ha demostrado que no se cumplió con dicho cometido, al no crear atractivos suficientes para la radicación de la actividad mayorista en los mercados protegidos, produciéndose la apertura de mercados no autorizados". Posteriormente, se refuerzan estos lineamientos permitiendo la comercialización directa entre productores y comercios minoristas (MEOySP, 1993). Esto sucedía en sintonía con la notable expansión que adquirían las cadenas de supermercados la Gran Distribución- que, aunque no alcanzaron a permear fuertemente en el sector frutihortícola, hacia fines de la década de 1990 alcanzarían su máximo nivel de participación de mercado en Argentina: 57 \%, considerando todos los sectores alimentarios (Pérez Martín, 2019).

Grenoville et al. (2019, p. 5) señalan que en el sinuoso camino transcurrido entre los orígenes del proyecto del MCBA y la actualidad, la definición de las agendas sectoriales y territoriales varió sustancialmente. En este sentido, destacan que "los mercados de frutas y verduras aprovecharon estos intersticios para establecerse muchas veces en los márgenes espaciales, económicos y normativos”. A su vez, Frigerio (comunicación personal, 15 de julio de 2016) agrega que el sistema de mercados mayoristas fue conformándose y articulando de manera autónoma sin ningún tipo de encuadramiento por parte del Estado, descomponiendo el plan original del MCBA. De todas formas, se ha ido configurando un sistema de comercialización mayorista frutihortícola caracterizado por la alta dispersión de los espacios comerciales y de los agentes económicos. En este proceso, tal como lo señalan García, Le Gall \& Mierez (2008), los productores han ido integrándose crecientemente en la comercialización, lo que significa que ha ido perdiendo importancia la comercialización vía consignatarios y en la propia quinta de los productores, conformando mercados mayoristas. Como resultado, con el correr de los años, tal como señalan Angelucci \& Bellingi (2005, p. 9), el MCBA “se encuentra en estado de aislamiento territorial y conforma un ámbito excluido de la planificación económica, social y urbana". De esta forma, desde 1984 a la actualidad tiene lugar la apertura de, al menos, 22 nuevos mercados mayoristas desde la puesta en marcha del MCBA, de acuerdo a lo relevado por Grenoville, Bruno, \& Radeljak (2020) (Figura 1). 


\section{FIGURA 1}

Localización de los mercados mayoristas del AMBA hasta 1984 y en la actualidad

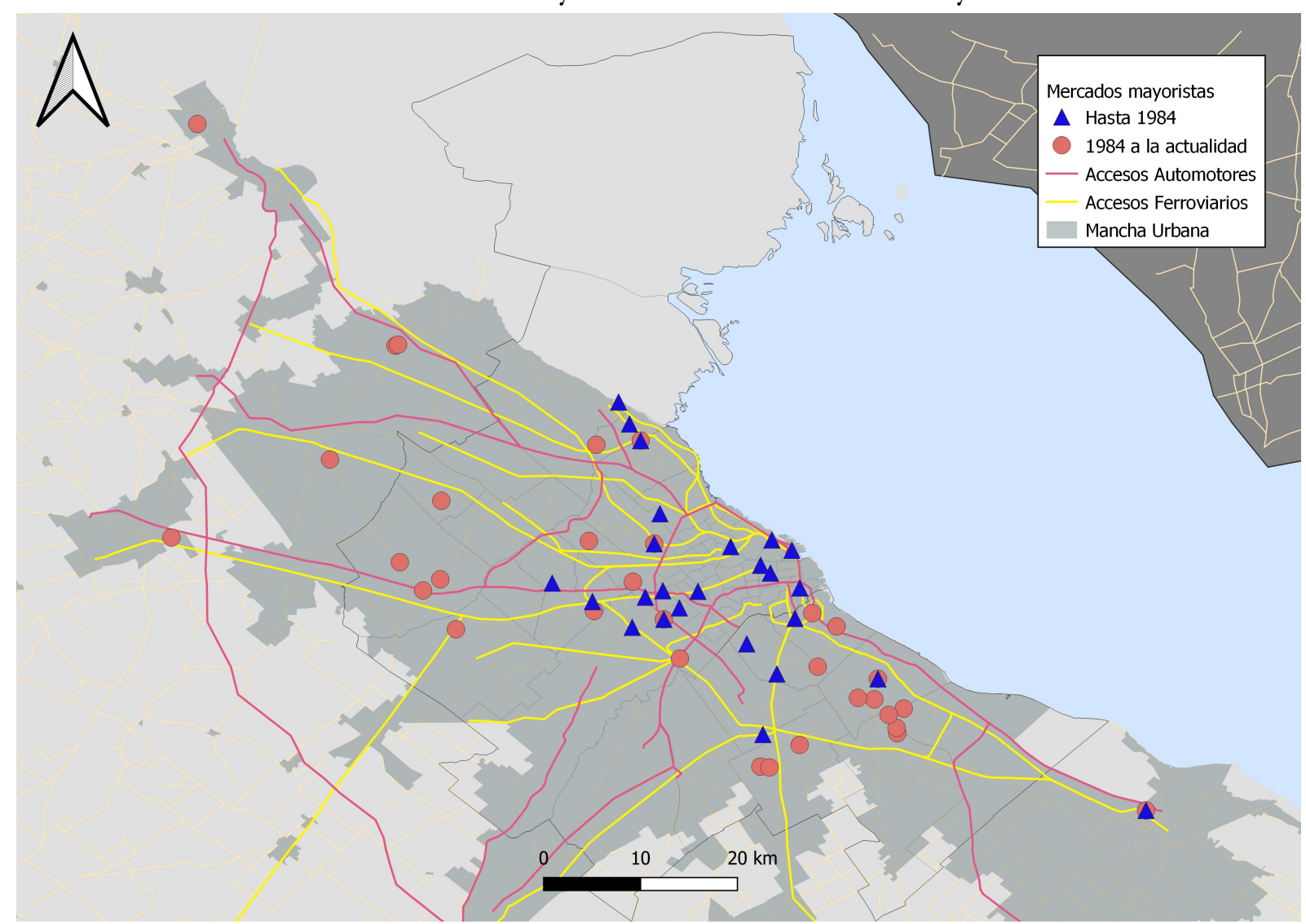

Fuente: elaboración propia en base a CFI (1962); SENASA (2020). Cartografía: Ramiro Suárez Paz

Por otra parte, el funcionamiento del MCBA desde su apertura a la actualidad tiene lugar en un contexto de intensa reducción del consumo de frutas y hortalizas en el AMBA, el cual cae de 173,4 kilogramos (kg) per cápita por año en 1985/1986 hasta $82,4 \mathrm{~kg}$ en 2012/2013, para incrementarse en el último relevamiento de 2017/2018, hasta alcanzar 90,1 kg (INDEC, 1986, 1997, 2005, 2013, 2020b). Aunque a priori podamos asumir que una caída en el consumo per cápita de frutas y hortalizas en el AMBA de $48 \%$ a lo largo de 33 años puede originarse en múltiples causas, la organización y el funcionamiento del entramado logístico y comercial -mayorista y minorista-, el cual se estructura alrededor del MCBA, seguramente sea una de ellas.

De esta forma, el rol del MCBA ha sido afectado sustancialmente por estos elementos con resultados muy claros: en sus 35 años de existencia, el MCBA operó, en promedio entre 1985 y 2019, 1,4 millones de toneladas de frutas y hortalizas, con muy leves variaciones a lo largo de esos años (alcanzando un coeficiente de variación de $7 \%$ ), y niveles máximos y mínimos en 1986 y en 1990, respectivamente, de 1,6 y 1,2 millones de toneladas (CMCBA, 2019a). Aunque ha guardado cierta relevancia para la dinámica de distintos subsectores en particular, a nivel regional y sectorial, el peso relativo del MCBA como articulador del abastecimiento mayorista del $\mathrm{AMBA}^{3}$ ha crecido hasta el 2005 y desde allí viene perdiendo peso, pasando de concentrar el $22 \%$ de la operación en la década de 1980 (se registran operaciones a partir de 1985), $41 \%$ en los años 90, $54 \%$ en los 2000 y $50 \%$ en la década de 2010. 
FIGURA 2

Evolución de la estimación del volumen de frutas y hortalizas ingresadas en el AMBA desde 1980 a 2019, volumen operado por el MCBA (eje derecho) y participación del MCBA en el total (eje izquierdo)

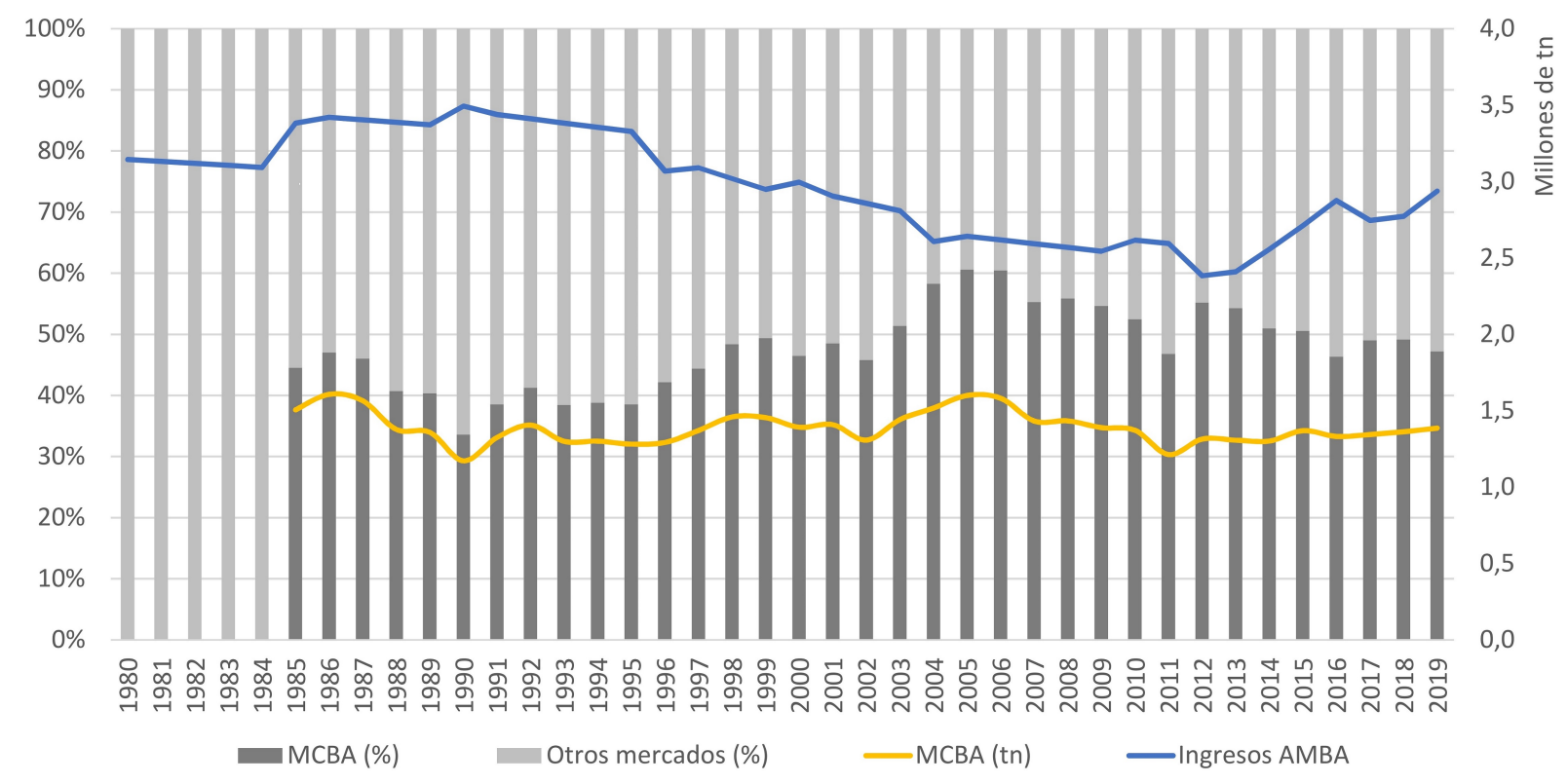

Fuente: elaboración propia en base a CMCBA (1971b, 2019a); INDEC (1986, 1997, 2005, 2013, 2020b)

En los últimos años, el MCBA fue objeto de distintas iniciativas parciales de refuncionalización y modernización, como las propuestas en 2000-2001, 2007 y 2017, aunque ninguna finalmente prosperó (Califano, 2001; Ministerio de Economía y Producción, 2007; Fernández Blanco, 2017). Recientemente, se ha mejorado la infraestructura y equipamiento en el MCBA con obras de pavimentación y la instalación de luminarias y se ha modificado su operatoria comercial, mejorando los resultados económicos (CMCBA, 2019b).

Sin embargo, el diseño y la gestión del sistema logístico y comercial frutihortícola a nivel metropolitano ha ido tomando forma autónoma, desarrollando su propia dinámica, respondiendo a lógicas operacionales que exceden las atribuciones del Mercado, sin que ello haya despertado un particular interés por parte de los distintos gobiernos involucrados en su administración (nacional, provincial y de la Ciudad Autónoma de Buenos Aires). En definitiva, desde la puesta en funcionamiento del MCBA a la actualidad se ha ido conformando una red de más de 40 mercados mayoristas en el conurbano bonaerense, siendo estos públicos, privados, o asociativos, y habiéndose originado tanto a partir de intereses particulares de los actores sectoriales, como de los actores políticos locales (Grenoville et al., 2020).

El desarrollo y la persistencia de los mercados mayoristas en el sector frutihortícola responde a cuestiones logísticas y comerciales: los mercados cumplen la función de intermediar entre la producción rural o periurbana y el consumo urbano. Allí se concentra un importante volumen de frutas y hortalizas, altamente perecederos, provenientes de múltiples orígenes geográficos (en el caso del MCBA, en promedio, localizados entre 80 y $1.100 \mathrm{~km}$ de distancia), y de distintos productos, tipos, calidades y estacionalidades. Aproximadamente unos 28.500 productores frutícolas y 19.000 hortícolas, radicados en todo el país (INDEC, 2020a), son responsables de la oferta primaria a los mercados para que allí se produzca el intercambio físico, la negociación comercial y la definición de precios. A su vez, los comercios minoristas demandan una oferta de amplia variedad y menor volumen, la cual comprende, en el caso del AMBA, a más de 11.800 verdulerías, 5.200 supermercados "chinos" y 1.500 sucursales de cadenas de supermercados. Particularmente, en el caso del AMBA, que tiene en promedio una baja densidad poblacional (5.656 
habitantes por $\mathrm{km} 2)$ y una mancha urbana muy expandida $(2.513 \mathrm{~km} 2)$, incluso en términos comparativos respecto de las seis ciudades latinoamericanas de más de 10 millones de habitantes (CAF, 2019), la cantidad de mercados mayoristas ofrece entonces una red de mayor cercanía tanto para productores como comerciantes minoristas. Esto no solo les garantiza una buena accesibilidad, sino que permite manejar, en mayor medida, las condiciones comerciales en las que se da el intercambio entre productores, operadores mayoristas y comerciantes minoristas.

En definitiva, el impacto que tiene la conformación actual de la red de mercados del AMBA tiene varias y muy complejas aristas. En virtud de su enorme heterogeneidad, el abasto alimentario podría adquirir mayor grado de organicidad como conjunto a través de una mayor presencia e interés estatal en el sector frutihortícola. En especial, si se promueven mayores niveles de coordinación particularmente desde la provincia de Buenos Aires, la cual aparece como el nivel de gobierno más adecuado para cumplir este rol, en función de que todos los mercados se localizan en territorio bonaerense. En cuanto a la eficiencia logística y comercial, tanto la circulación -y el consecuente gasto logístico- como la multiplicidad de compras y ventas mayoristas que se dan en una red de mercados tan atomizada, traen aparejados diversos impactos negativos. El primero, y más evidente, es en el proceso de formación de precios, lo que termina repercutiendo en la accesibilidad económica por parte de la población. A su vez, una red de mercados de estas características incrementa la generación de pérdidas, que en el sector frutihortícola son muy elevadas (en promedio, 32 $\%$ de lo producido se pierde desde la cosecha hasta alcanzar los puntos de venta urbanos) (Rivas, Blengino, Álvarez de Toledo, \& Franco, 2015). Siendo este un aspecto relevante por cuestiones ambientales, también termina impactando en los precios minoristas, dado que el comerciante debe cargar estas pérdidas entre sus costos. A su vez, en una red tan expandida, la generación y difusión de información de mercado tal como volúmenes operados, calidades y precios queda restringida - paradójicamente- a pocos actores, generándose una gran cantidad de negociaciones individuales que no terminan de constituir un mercado de referencia mayorista transparente y justo entre las partes, lo que restringe el poder de negociación, particularmente a pequeños y medianos productores y comerciantes. Por último, en términos sanitarios, la multiplicidad de mercados y la superposición de funciones de control desde los distintos niveles de gobierno también conlleva consecuencias negativas. En este sentido, Mac Loughlin et al. (2018) han recogido muestras de cinco productos frutihortícolas en verdulerías de las ciudades de Buenos Aires y La Plata, encontrando que el $65 \%$ de ellas contenían residuos de distintos agroquímicos, y que el $39 \%$ no estaba en condiciones de ser consumidas, dada la normativa vigente. Sin embargo, y tal como se ha mencionado, una de las cuestiones positivas de la red actual de mercados mayoristas en el AMBA es la buena accesibilidad con la que cuentan tanto productores como comerciantes minoristas, dada la cercanía y opciones disponibles. En definitiva, atendiendo tanto a las cuestiones comerciales, la formación de precios, la calidad, así como a lo sanitario, parece relevante plantearse cuáles son los impactos que un entramado logístico y comercial de estas características provocan en la seguridad alimentaria y nutricional de la población, dado que el consumo de frutas y hortalizas ha ido disminuyendo en las últimas décadas, cubriendo, en la actualidad y a nivel nacional, solamente 2 de las 5 porciones diarias recomendadas (Secretaría de Gobierno de Salud, 2019).

\section{REFLEXiOnES FinAles}

El proyecto del MCBA constituye la iniciativa de carácter estatal de mayor relevancia en la historia de nuestro país en lo referido a la planificación de un sistema de abastecimiento alimentario de alcance metropolitano. A pesar de la importante inestabilidad política que caracterizó al período 1960-1983, con eje en los tres golpes de Estado, el plan original de constituir un mercado mayorista -de impronta desarrollista en sus orígenes- adquirió una inercia tecnocrática tal que llevó al proyecto a persistir en el tiempo, materializándose finalmente en el marco de la última dictadura militar. 
El proyecto fue principalmente ideado y motorizado desde la Ciudad de Buenos Aires, cuando se hicieron evidentes las externalidades negativas que surgían del heterogéneo e ineficiente sistema de abastecimiento alimentario existente en los años sesenta. Dada su centralidad, la ciudad capital pudo incidir en la agenda pública e involucrar a la Nación y a la Provincia de Buenos Aires para buscar, dentro del complejo andamiaje institucional del régimen federal argentino, una solución fuera de su territorio. El proyecto de creación del mercado único pudo avanzar a pesar de la alta inestabilidad política cívico-militar, mientras que cada administración fue dejando su impronta en la medida en que el mismo iba ganando mayores grados de consenso. Sin embargo, el momento en que la obra del MCBA acelera su construcción y se concreta materialmente es durante el régimen de facto del Proceso de Reorganización Nacional, aunque paradójicamente- su apertura formal no se realiza hasta el advenimiento de la democracia. Respecto a esto, Cacciatore (1993) destacaba:

Nuestra administración apoyó desde el principio los objetivos del Mercado Central y aportó recursos económicos para llevar adelante las obras y el equipamiento del mismo (...) los grupos de presión que manejaban el ex mercado de Abasto (...) desvirtuaron los objetivos orientadores de la creación del MCBA y procuraron convertirlo en un nuevo 'elefante blanco' (p. 316).

Analizando este proceso a más de cincuenta años de su génesis, es posible distinguir, en principio, una gran complejidad en el proceso de planificación, en la ejecución de la obra y, finalmente, en la puesta en marcha del Mercado, lo cual se evidencia no solo por el largo tiempo transcurrido en cada etapa, sino también por las marchas y contramarchas que caracterizó a cada una. Es importante destacar que esta complejidad, propia de la implementación de agendas públicas estratégicas con incidencia territorial, evidentemente excede los contextos coyunturales. Este punto resulta central a la hora de caracterizar el dispositivo institucional al que se debió apelar para que el proyecto de mercado concentrador metropolitano pudiera seguir su curso y gravitar en la gobernanza del abastecimiento alimentario del AMBA.

Por lo tanto, esta gran intervención urbana es el resultado de la combinación de un proyecto surgido de la etapa desarrollista de principios de los años sesenta, complementado con la exorbitante disponibilidad de financiamiento externo propia de la etapa de valorización financiera de Martínez de Hoz, lo que, a su vez, se articuló con la lógica militar que propiciaba la construcción de grandes obras de infraestructura. La impronta modernizadora del proyecto junto con su origen europeo fueron aspectos políticamente atractivos en ambas etapas, aunque la fuerte intervención estatal que proponía la legislación de MIN -inspirada en la francesa y diseñada a la medida del MCBA-, distaba claramente del liberalismo económico que se había implantado en nuestro país desde mediados de los años setenta. Por otra parte, no pareciera haber existido una interacción coherente entre el diseño del proyecto, la ejecución de la obra, la puesta en funcionamiento del Mercado y su articulación con el sistema de mercados existente en ese momento, lo cual requería contar con una perspectiva de gestión metropolitana. En definitiva, el MCBA -que se inauguró en 1984- había sido planificado casi 25 años antes de su apertura en condiciones muy distintas.

Resulta claro que la planificación y gestión de una política de abastecimiento de alimentos metropolitana de semejante magnitud demanda consensos e involucramiento de actores que ni la dictadura -a través de "medidas coadyuvantes y coercitivas"-, ni los distintos gobiernos democráticos -a través de un juego más equilibrado de los poderes del Estado-, pudieron construir aprovechando las posibilidades que brinda esta gran obra de infraestructura que es el MCBA. A más de 35 de años de su inauguración, el MCBA no solo no se constituyó como el único mercado concentrador en el AMBA, sino que -a pesar de tener una dirección interjurisdiccional- tampoco ejerce funciones de articulación del sistema de mercados de la región porque las mismas no le han sido formalmente delegadas. Sumado a esto, a una década de su inauguración su funcionamiento fue afectado decisivamente a partir de las disposiciones desregulatorias implementadas durante los años 1990. Como se ha señalado, el MCBA no ha logrado imponer en ningún momento un elevado nivel de concentración de la operación mayorista y viene perdiendo participación en el volumen, debilitando su centralidad. Sin embargo, el organismo aún conserva un potencial de coordinación de enorme 
importancia para ordenar el abasto del AMBA entrelazado con la Provincia de Buenos Aires, donde se localizan todos los mercados mayoristas y se concentra buena parte de la oferta productiva y la demanda minorista. A pesar de que el MCBA aún se sostiene como el espacio transaccional de frutas y hortalizas más importante a nivel nacional y metropolitano, constituyéndose como un mercado de referencia, se deben desarrollar estrategias para que crezca su operación, ganando relevancia y evitando que la inercia planteada licúe su funcionamiento en el corto plazo. A su vez, se podría considerar ampliar la funcionalidad del MCBA a otros sectores alimentarios que también presentan importantes desafíos logísticos y comerciales para abastecer el AMBA -como carnes, lácteos y otros alimentos secos-, aprovechando la gran superficie vacante y la conexión ferroviaria, entre otros elementos.

\section{Referencias Bibliográficas}

Alfonsín, R. (1984). Palabras del Señor Presidente de la Nación Doctor Raúl R. Alfonsín, en la inauguración del Mercado Central de Buenos Aires, el día 15 de octubre de 1984. Recuperado el 11 de febrero de 2020 de http s://bit.ly/2JyPsrY

Angelucci, R. H., \& Bellingi, G. A. (2005). La problemática del abasto en la región metropolitana y la gestión del Mercado Central de Buenos Aires. Presentado en VII Seminario Nacional de la Red de Centros Académicos para el Estudio de Gobiernos Locales, Ciudad Autónoma de Buenos Aires.

Argentina, paraíso de los especuladores (1964). Revista Panorama. Recuperado de http://bit.ly/39S87HQ

Barsky, A. (2014). Gestionando la diversidad del territorio periurbano desde la complejidad de las instituciones estatales (Tesis Doctoral, Universitat Autònoma de Barcelona, Barcelona). Recuperado de https://bit.ly/335s3G0

Braun Estrugamou, G. (1981). El Mercado Central de Buenos Aires. Futurable - Revista de la Fundación Argentina Año 2000, 1(10), 55-59.

Búscase el modo de operar el Mercado Central, que costó U\$S 600 millones (4 de diciembre de 1980). Diario La Prensa.

Cacciatore, O. A. (1993). Sólo los hechos. Ciudad de Buenos Aires: Metáfora Editorial.

CAF. (2019). Observatorio de movilidad urbana. Banco de Desarrollo de América Latina. Recuperado de https://b it.ly/2NuN5Xi

CAL. (1980). Exp.: 24/1980 - Ratificar el convenio tripartito del 13/07/1978 por el que se aumenta el capital de la CMCBA. Comisión de Asesoramiento Legislativo.

CAL. (1983a). Exp. 1493/83 - Reducción alícuota IVA en los Mercados de Interés Nacional. Comisión de Asesoramiento Legislativo.

CAL. (1983b). Expediente 74.890/83. Comisión de Asesoramiento Legislativo.

Calcagno, E. (1987). Los bancos transnacionales y el endeudamiento externo en la Argentina. Santiago de Chile: CEPAL. Recuperado de https://bit.ly/3IImBiy

Califano, S. (18 de diciembre de 2001). El Mercado Central piensa en crecer. La Nación. Recuperado de http://bit. ly/2ITW68H

Caride, H. (1999). La idea de Conurbano bonaerense, 1925-1947. Los Polvorines: Universidad Nacional de General Sarmiento.

CFI. (1962). Estudio preliminar sobre el problema del abastecimiento en la Capital Federal y el Gran Buenos Aires. Ciudad de Buenos Aires, Argentina: Consejo Federal de Inversiones.

CMCBA. (1971a). Concurso de méritos, titulos y antecedentes de profesionales o firmas consultoras para la ejecución de los proyectos básicos correspondientes a la siguiente obra. Tapiales, Buenos Aires: Corporación del Mercado Central de Buenos Aires.

CMCBA. (1971b). Los mercados mayoristas de frutas y hortalizas del Area Metropolitana. Tapiales, Buenos Aires: Corporación del Mercado Central de Buenos Aires. 
CMCBA. (1973). Evaluación Económica y Programación Financiera del Mercado Central de Buenos Aires. Tapiales, Buenos Aires: Corporación del Mercado Central de Buenos Aires.

CMCBA. (2019a). Estadísticas volúmenes ingresados 1985-2019. Corporación del Mercado Central de Buenos Aires.

CMCBA. (2019b). Informe de gestión 2016-2019. Tapiales, Buenos Aires: Corporación del Mercado Central de Buenos Aires. Recuperado de http://bit.ly/2ITzdCv

ERMCBA. (1963a). Informe preliminar sobre la figura comercial y funcional del Mercado Central. Ciudad de Buenos Aires, Argentina: Ente Realizador del Mercado Central de Buenos Aires.

ERMCBA. (1963b). Informe Reservado. Ciudad de Buenos Aires, Argentina: Ente Realizador del Mercado Central de Buenos Aires.

Fernández Blanco, P. (13 de mayo de 2017). Macri relanza el Mercado Central, que copiará al de Barcelona. La Nación. Recuperado de http://bit.ly/3bajfjz

Frigerio, N. (1973). Alternative wholesale facility arrangements for fresh fruits and vegetables in the Buenos Aires metropolitan region. Michigan State University. Recuperado de https://bit.ly/3kTbvY4

Frigerio, N. (1976). El impacto potencial de los nuevos mercados mayoristas sobre los costos de distribución de alimentos en áreas urbanas. San José: IICA.

García, M., Le Gall, J., \& Mierez, L. (2008). Comercialización tradicional de hortalizas de la región metropolitana bonaerense. Boletin horticola, 14, 8-15.

Gauto, E., \& Ninin, S. (1979). La comercialización de frutas frescas en el área metropolitana (Tesis de Grado). Facultad de Agronomía - Universidad de Buenos Aires, Ciudad de Buenos Aires, Argentina.

Grenoville, S., Bruno, M., \& Radeljak, F. (2020). Los Mercados Mayoristas de frutas y verduras del Area Metropolitana de Buenos Aires (AMBA): Caracterización, diagnóstico y propuestas para seguir avanzando. Ciudad Autónoma de Buenos Aires, Argentina. Recuperado de https://bit.ly/3082ke3

Grenoville, S., Radeljak, F., \& Bruno, M. (2019). Informalidad y conflicto de intereses en el abastecimiento mayorista de frutas y verduras del Area Metropolitana de Buenos Aires. Presentado en XI Jornadas Interdisciplinarias de Estudios Agrarios y Agroindustriales, Facultad de Ciencias Economías, Universidad de Buenos Aires, Ciudad Autónoma de Buenos Aires, Argentina.

HCDN. (1983). Exp.: 676/1983 Ratkovic y otros. Solicitar al Poder Ejecutivo la puesta en marcha del Mercado Central de Buenos Aires. Honorable Cámara de Diputados de la Nación.

INDEC. (1986). Encuesta de Gastos e Ingresos de los Hogares 1985-1986. Argentina: Instituto Nacional de Estadística y Censos - Ministerio de Economía.

INDEC. (1997). Encuesta Nacional de Gastos de los Hogares 1996-1997. Argentina: Instituto Nacional de Estadística y Censos - Ministerio de Economía.

INDEC. (2005). Encuesta Nacional de Gastos de los Hogares 2004-2005. Argentina: Instituto Nacional de Estadística y Censos - Ministerio de Economía.

INDEC. (2013). Encuesta Nacional de Gastos de los Hogares 2012-2013. Argentina: Instituto Nacional de Estadística y Censos - Ministerio de Economía.

INDEC. (2019). Encuesta Nacional de Gastos de los Hogares 2017-2018 - Informe de gastos. Argentina: Instituto Nacional de Estadística y Censos - Ministerio de Economía.

INDEC. (2020a). Censo Nacional Agropecuario 2018 - Resultados Preliminares. Argentina: Instituto Nacional de Estadística y Censos - Ministerio de Economía.

INDEC. (2020b). Encuesta Nacional de Gastos de los Hogares 2017-2018. Argentina: Instituto Nacional de Estadística y Censos - Ministerio de Economía.

INDEC. (2020c). Población - Proyecciones y estimaciones. Argentina: Instituto Nacional de Estadística y Censos Ministerio de Economía.

Jajamovich, G., \& Menazzi, L. (2012). Políticas urbanas en un contexto de dictadura militar. Algunos interrogantes a partir de Buenos Aires (1976-1983). Revista Bitácora Urbano Territorial, 20(1). 
Link, D. (1974). Modernización del Sistema de Mercados Mayoristas de Frutas y Hortalizas de Buenos Aires (Documento de Trabajo N.o 27). Roma: FAO.

Mac Loughlin, T. M., Peluso, M. L., Etchegoyen, M. A., Alonso, L. L., de Castro, M. C., Percudani, M. C., \& Marino, D. J. (2018). Pesticide residues in fruits and vegetables of the argentine domestic market: Occurrence and quality. Food control, 93, 129-138.

MCBA. (1960a). Ordenanza No 16.931 - Expendio al público de carne trozada envasada en bolsitas de polietileno. Municipalidad de la Ciudad de Buenos Aires. Recuperado de https://bit.ly/33KUkS7

MCBA. (1960b). Ordenanza No 16.932 - Locales de venta de productos alimenticios. Municipalidad de la Ciudad de Buenos Aires. Recuperado de https://bit.ly/2RzPCjV

MCBA. (1961). Ordenanza No 17.342 - Se declara obligatoria la bigienización y pasteurización de la leche de consumo en la ciudad de Buenos Aires. Municipalidad de la Ciudad de Buenos Aires. Recuperado de https://bit.ly/2Id2g7b

MCBA. (1964). Ordenanza No 19.604 - Venta de leche en negocios que no cuenten con elementos de refrigeración adecuada. Municipalidad de la Ciudad de Buenos Aires. Recuperado de https://bit.ly/3g8Wosj

MCBA. (1967). Ordenanza No 22.817 - Mercado Central. Municipalidad de la Ciudad de Buenos Aires. Recuperado de https://bit.ly/3oo2rvR

MEOySP. (1993). Resolución No 1.196 - Deróganse normas que prohíban la venta directa. Ministerio de Economía, Obras y Servicios Públicos. Recuperado de https://bit.ly/3lFJzqp

Ministerio de Economía y Producción. (2007). Lineamientos para la conformación de un corredor multimodal de transporte puerto de Buenos Aires-Mercado Central-Aeropuerto de Ezeiza. Mercado Central de Buenos Aires como cabecera multimodal de transporte de carga (fluvial, automotor, ferroviario).

Miscelánea política (1965). Revista Primera Plana. Recuperado de http://bit.ly/2TOKI4k

Navarrete Ulloa, C. A. (2020). Gobernanza Metropolitana: Perspectivas desde la Nueva Agenda Urbana. Revista de Estudios Metropolitanos en Gobernanza, 2, 33.

ODSA-UCA. (2019). Incidencia de la inseguridad alimentaria severa y total para los Hogares y la Población en la Argentina urbana 2010-2019. Universidad Católica Argentina. Recuperado de http://bit.ly/2uCVwZy

OPR. (1968). Informe Preliminar-Etapa 1959-1960. Ciudad de Buenos Aires: Organización del Plan Regulador.

PEN. (1962a). Decreto No 7.703 - Declara a la Municipalidad de la Ciudad de Buenos Aires tendrá a su cargo la organización y promoción del abastecimiento de articulos de primera necesidad en la Capital Federal. Poder Ejecutivo Nacional. Recuperado de https://bit.ly/39JNOyL

PEN. (1962b).Decreto-Ley $N^{\circ} 13.435$ - Probibición de establecimiento de mercados mayoristas de alimentos en la Capital Federal. Poder Ejecutivo Nacional. Recuperado de https://bit.ly/3lHWqIS

PEN. (1963). Decreto No 3.287 - Ente Realizador del Mercado Central de Buenos Aires. Poder Ejecutivo Nacional. Recuperado de https://bit.ly/2IhFoDI

PEN. (1967). Ley No 17.422 - Corporación del Mercado Central de Buenos Aires. Poder Ejecutivo Nacional. Recuperado de https://bit.ly/2VBvkIL

PEN. (1970). Decreto No 46 - Apruébanse las Políticas Nacionales. Poder Ejecutivo Nacional. Recuperado de https:/ /bit.ly/33IrTEq

PEN. (1971). Ley No 19.227 - Mercados de Interés Nacional. Poder Ejecutivo Nacional. Recuperado de https://bit.l y/3mIG3gv

PEN. (1973a).Decreto $N^{\circ} 146$ - Se declaran incorporados al servicio público diversos mercados mayoristas privados y ciertos remates de frutas. Poder Ejecutivo Nacional. Recuperado de https://bit.ly/2JtNZUx

PEN. (1973b). Decreto No 150 - Declárense incorporados al servicio público los remates de grutas organizados por Corporación Frutícola Argentina y Asociación Argentina de Productores de Frutas, en la Ciudad de Buenos Aires. Poder Ejecutivo Nacional. Recuperado de https://bit.ly/3mMHjiv

PEN.(1973c).Decreto No 187 -Declara incorporados al serviciopúblico de Mercados de Interés Nacional. Poder Ejecutivo Nacional. Recuperado de https://bit.ly/36J9E3H 
PEN. (1973d). Decreto No 776 - Aprúebase el Plan Trienal para la Reconstrucción y la Liberación Nacional. Poder Ejecutivo Nacional. Recuperado de https://bit.ly/33MQzfb

PEN. (1978). Decreto No 2.693 - Desígnase asesores del área de Mercados de Interés Nacional para trasladarse a la ciudad de Paris, Francia. Poder Ejecutivo Nacional. Recuperado de https://bit.ly/36FwB7W

PEN. (1990). Decreto $N^{o} 2.510$ - Adécuase la reglamentación de la Ley del IVA. Poder Ejecutivo Nacional. Recuperado de https://bit.ly/3giKxYD

PEN. (1991). Decreto No 2.284 - Desregulación Económica. Poder Ejecutivo Nacional. Recuperado de https://bit.ly/ $2 \mathrm{~L} 8 \mathrm{Npfg}$

PEPBA. (1962). Decreto $N^{o} 11.338$ - Probibición de la habilitación de mercados mayoristas de artículos alimenticios en los partidos del conurbano bonaerense. Poder Ejecutivo de la Provincia de Buenos Aires. Recuperado de https:/ /bit.ly/3gbfvlq

PEPBA. (1963). Decreto No 5.053. Poder Ejecutivo de la Provincia de Buenos Aires. Recuperado de https://bit.ly/3 9s $\mathrm{TwFl}$

PEPBA. (1984). Ley $N^{\circ} 10.202$ - Prohibiendo ventas mayoristas de verduras, frutas y hortalizas en diversos partidos de la Provincia. Poder Ejecutivo de la Provincia de Buenos Aires. Recuperado de https://bit.ly/3fQmKiq

Pérez Martín, J. (2015). Políticas metropolitanas de abastecimiento de alimentos: El caso del Mercado Central de Buenos Aires. Presentado en IX Jornadas Interdisciplinarias de Estudios Agrarios y Agroindustriales, Facultad de Ciencias Económicas, Universidad de Buenos Aires, Ciudad Autónoma de Buenos Aires, Argentina.

Pérez Martín, J. (2019). De la gran distribución al omni-channel: Estrategias de negocios y poder de negociación en el abastecimiento de productos lácteos y frutihorticolas en el Área Metropolitana de Buenos Aires. Presentado en VII Seminario Internacional Ciudad, Comercio y Consumo «Abriendo nuevas perspectivas para los estudios geográficos», Ciudad Autónoma de Buenos Aires, Argentina.

Pírez, P. (2005). Expansión territorial, privatización y fragmentación en la configuración metropolitana de Buenos Aires. Cadernos Metrópole, 13, 11-46.

Pons, R. E. (1981). Estudio de la operativa comercial del Mercado Central. Ciudad de Buenos Aires, Argentina: Consejo Federal de Inversiones.

Ratifican que el Mercado Central abrirá el día 24 (11 de mayo de 1983). Diario Clarín.

Rivas, A., Blengino, C., Álvarez de Toledo, B., \& Franco, D. (2015). Hacia la reducción de pérdidas y desperdicios de alimentos en Argentina. Revista Alimentos Argentinos, 65.

Salvia, A., Tuñón, I., \& Musante, B. (2012). La inseguridad alimentaria en la Argentina. Hogares urbanos. Año 2011. Ciudad Autónoma de Buenos Aires, Argentina: Observatorio de la Deuda Social Argentina - Universidad Católica Argentina. Recuperado de https://bit.ly/3n7WpQn

SCyNE. (1977). Resolución $N^{\circ} 3$ - Dicta normas para los mercados mayoristas incorporados al servicio público. Secretaría de Comercio y Negociaciones Económicas. Recuperado de https://bit.ly/3lJrAQ2

Secretaría de Gobierno de Salud. (2019). $4^{\circ}$ Encuesta Nacional de Factores de Riesgo-Informe Definitivo. Ciudad Autónoma de Buenos Aires, Argentina. Recuperado de https://bit.ly/3hxkUTg

Seidler, E. (2001). Wholesale Market Development - FAO's Experience. Presentado en 22nd Congress of the World Union of Wholesale Markets, Durban, South Africa.

SENASA. (2020). Registro de Mercados Mayoristas del Sistema de Control de Productos Frutihorticolas Frescos (SICOFHOR) [Informe no publicado]. Argentina: Servicio Nacional de Sanidad y Calidad Agroalimentaria Ministerio de Agricultura, Ganadería y Pesca.

S.A. Mercado de Abasto Proveedor (14 de octubre de 1984). Diario La Prensa.

US Bureau of Labor Statistics. (2020). CPI Inflation Calculator. Recuperado de http://bit.ly/3aXQwOG

Viteri, M. L. (2010). Fresh Fruit and Vegetables: A World of Multiple Interactions: The Case of the Buenos Aires Central Wholesale Market (BACWM) (Tesis Doctoral). Wageningen University, Wageningen, Países Bajos. 


\section{Notas}

1 Hogares que expresaron haber reducido la porción de alimentos consumidos y/o experimentado hambre en los últimos 12 meses por problemas económicos (Salvia, Tuñón, \& Musante, 2012).

2 De acuerdo a la tasa de inflación de Estados Unidos a febrero 2020 (Consumer Price Index) (US Bureau of Labor Statistics, 2020).

3 A partir de los datos de consumo hogareño de frutas y hortalizas, se estimó el volumen total a nivel del AMBA ponderándolo con el crecimiento poblacional, incorporando un porcentaje promedio de pérdidas de $21 \%$-entre el comercio minorista y la operación mayorista- y, finalmente, asumiendo un incremento de entre $20 \%$ y $35 \%$ de volumen consumido fuera de los hogares entre la década de 1980 y la de 2010, con saltos de $5 \%$ por cada década. 